The Journal of Laryngology \& Otology

http://journals.cambridge.org/JLO

Additional services for The Journal of Laryngology \& Otology:

Email alerts: $\underline{\text { Click here }}$

Subscriptions: $\underline{\text { Click here }}$

Commercial reprints: $\underline{\text { Click here }}$

Terms of use : $\underline{\text { Click here }}$

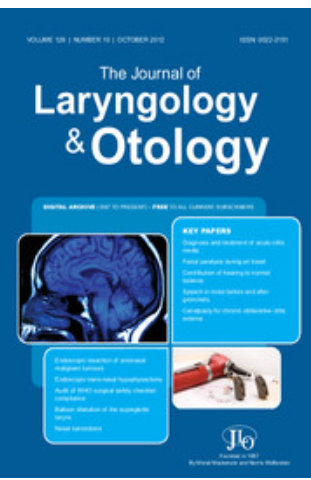

\title{
Aspergillus mastoiditis in a patient with acquired immunodeficiency syndrome
}

P. D. Yates, T. Upile, P. R. Axon and J. de Carpentier

The Journal of Laryngology \& Otology / Volume 111 / Issue 06 / June 1997, pp 560 - 561

DOI: 10.1017/S0022215100137909, Published online: 29 June 2007

Link to this article: http://journals.cambridge.org/abstract_S0022215100137909

How to cite this article:

P. D. Yates, T. Upile, P. R. Axon and J. de Carpentier (1997). Aspergillus mastoiditis in a patient with acquired

immunodeficiency syndrome. The Journal of Laryngology \& Otology, 111, pp 560-561 doi:10.1017/S0022215100137909

Request Permissions : $\underline{\text { Click here }}$ 


\title{
Clinical Records
}

\section{Aspergillus mastoiditis in a patient with acquired immunodeficiency syndrome}

\author{
P. D. Yates, F.R.C.S.*, T. Upile, M.B., Ch.B.*, P. R. Axon, F.R.C.S.*, J. De Carpentier, F.R.C.S. $\dagger$
}

\begin{abstract}
We present the case history of a patient who was severely immunocompromised due to infection with the human immunodeficiency virus (HIV), and who subsequently developed acute mastoiditis due to Aspergillus fumigatus. Fungal otomastoiditis is a rarely reported complication of HIV infection. A high index of suspicion is required in these patients to facilitate early diagnosis and appropriate therapy.
\end{abstract}

Key words: Mastoiditis; Aspergillosis; Human immunodeficiency virus

\section{Case report}

We present the case of an 18-year-old male with haemophilia A, hepatitis B and AIDS. The patient presented with a three-month history of recurrent leftsided ear infections which had been treated with various topical antibiotic preparations. For two weeks he had had worsening left otalgia. His hearing in his left ear was subjectively reduced, but there was no history of otorrhoea, vertigo or tinnitus. He complained of altered sensation over the left side of his face and pinna.

Examination revealed an erythematous left ear with loss of the post-auricular sulcus. There was no post-auricular fluctuance, no discharge in the external auditory meatus and the tympanic membrane appeared dull. The right ear was normal. He was pyrexial and systemically unwell. His white cell count was $3.0 \times 10^{9} / 1$ (neutrophils 75 per cent, lymphocytes 16 per cent and monocytes eight per cent). His CD4 count was one per cent of normal. A computed tomography (CT) scan demonstrated erosion of the left mastoid air cells and bone overlying the lateral sinus (Figure 1). There was no evidence of intracranial spread of infection. A diagnosis of acute mastoiditis was made and treatment with intravenous ceftazidime and gentamicin was commenced.

Although initially his condition improved, evidence of mastoid infection persisted and 12 days following admission it was decided to explore his mastoid. Due to his systemic condition it was not possible to perform a preoperative audiogram.

At operation a periosteal flap was elevated to reveal an abscess cavity full of granulations but no frank pus. The posterior wall and bony cortex overlying the mastoid air cells had been eroded by the infective process. A radical mastoidectomy was performed and biopsies of the granulations were sent for culture. Culture results from the surgical specimens demonstrated Aspergillus fumigatus to be the causative organism. Oral itraconazole was hence commenced and his early post-operative recovery was uneventful. At his first post-operative check the mastoid was clinically clear and he was symptom-free. Unfortunately, on the 14th post-operative day he had a massive upper gastrointestinal haemorrhage and died.

\section{Discussion}

Patients with AIDS are susceptible to multiple fungal pathogens such as Candida sp., Pneumocystis carinii and Cryptococcus neoformans. Aspergillosis is the commonest

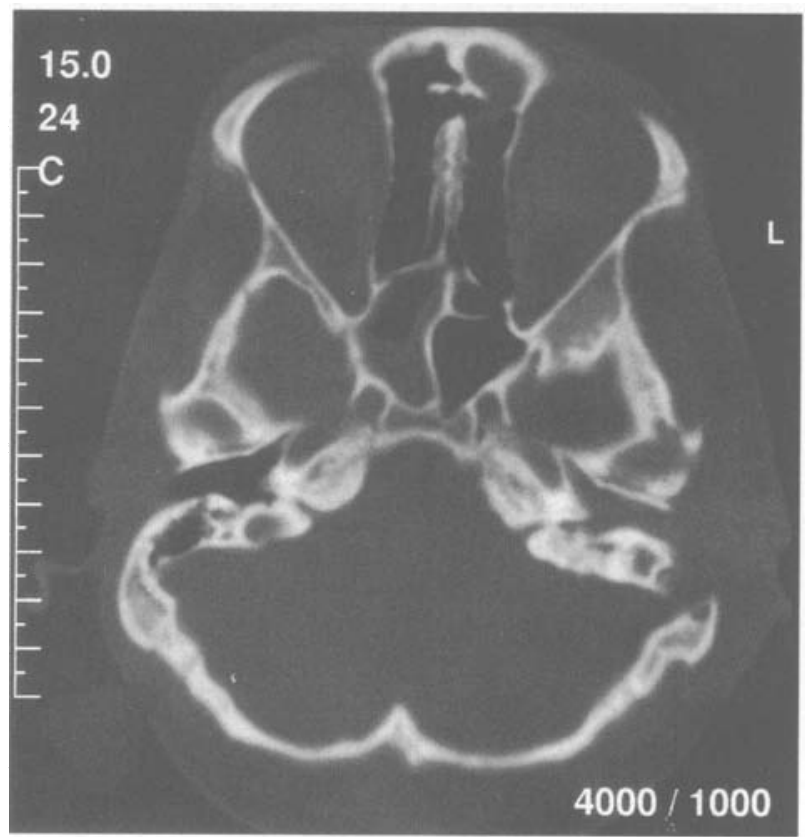

Fig. 1

CT scan demonstrating erosion of the left mastoid air cells and bone overlying the lateral sinus.

From the Departments of Otolaryngology, Manchester Royal Infirmary*, Manchester, and Royal Preston Hospital†, Preston, UK. Accepted for publication: 26 March 1997. 
human mould infection and the AIDS patient is highly susceptible to infection. Several autopsy series have been performed and demonstrate that the frequency of aspergillosis varies between 0 and nine per cent, with the overall frequency approximately four per cent from 1052 autopsies (Denning, 1992).

The commonest body site to be involved by aspergillosis in AIDS is the lung, although the brain seems to be particularly infected in AIDS patients compared with other host groups (Denning, 1992). The majority of AIDS patients who develop aspergillosis have a neutropenia and/or are receiving corticosteroids. Aspergillus otomastoiditis has been described in eight published cases (Lamprecht et al., 1990; Reiss et al., 1991; Strauss and Fine, 1991; Hall and Farrior, 1993; Stanley et al., 1988). Aspergillus has also been reported as the cause of malignant otitis externa in an immunocompetent host (Cunningham et al., 1988). In this patient, as in our patient, there was erosion of the posterior bony canal resulting in an auto-mastoidectomy.

The increased risk of developing aspergillosis in AIDS is probably attributable to the gradual immunological decline in the later stages of AIDS which also profoundly affects neutrophil and macrophage function in addition to $T$ helper-cell function. There is also a possible link to multiple antibiotic usage (Denning, 1992).

Aspergillus fumigatus may obtain access to the middle ear in variable ways. Initial fungal otitis externa with preexisting perforation may provide a route of infection. AIDS patients often develop lymphoid hyperplasia, which includes the adenoids. This may lead to Eustachian tube obstruction with secondary serous or acute otitis media. The anaerobic conditions so produced, along with the host immuno-incompetence favour fungal colonization of the middle ear cleft via the Eustachian tube.

The treatment of aspergillosis in AIDS is problematic and the response to treatment is considerably inferior to that observed in non-AIDS patients (Denning et al., 1991). When an immunocompromised patient with fungal otomycosis fails to resolve with aural toilet and topical anti-fungal agents, a CT scan is indicated to evaluate the extent of the disease. Once fungal otomastoiditis is established, successful treatment is dependent upon early diagnosis with surgical debridement of the infected tissues, followed by oral itraconazole (Lamprecht et al., 1990; Denning et al., 1991). Doses should at least $400 \mathrm{mg}$ daily, preceded by a loading of $600 \mathrm{mg}$ daily for the first four days.
In our patient, the symptoms of mastoiditis persisted despite treatment with broad spectrum antibiotics. His fungal otomastoiditis responded well to aggressive surgical debridement and oral itraconazole. With a high index of suspicion we might have operated on him sooner, although in this case, this would not have influenced his final outcome as his death was of unrelated pathology.

\section{Conclusion}

Although at present Aspergillus mastoiditis appears to be a rare complication of AIDS, the frequency of this complication should be expected to increase as more patients develop AIDS and live for longer periods. A high index of suspicion is required to ensure an early diagnosis and effective treatment of this potentially lethal infection.

\section{References}

Cunningham, M., Yu, V. L., Curtin, H. (1988) Necrotizing otitis externa due to Aspergillus in an immunocompetent host. Archives of Otolaryngology, Head and Neck Surgery 114(5): 554-556.

Denning, D. W. (1992) Invasive aspergillosis in AIDS. An overview. Journal of Mycological Medicine 2(Suppl. I): $35-41$.

Denning, D. W., Pappas, P. G., Kauffman, C. A., Hostetler, J. S., Lee, J. Y., Stevens, D. A. (1991) Oral Itraconazole Therapy of Invasive Aspergillosis. Interscience Conference on Antimicrobial Agents and Chemotherapy, Chicago, Abstr. 1158.

Hall, P. J., Farrior, J. B. (1993) Aspergillus mastoiditis. Otolaryngology-Head and Neck Surgery 108(2): 167-70.

Lamprecht, J., Khun, A. G., Sauer, S. (1990) Aspergillus mastoiditis in infected granulomatosis, a case report. Laryngo-Rhino-Otologie (Stuttgart) 69(6): 341-343.

Reiss, P., Hadderingh, R., Schot, L. J., Danner, S. A. (1991) Invasive external otitis caused by Aspergillus fumigatus in two patients with acquired immunodeficiency syndrome. Trends in the Management of Systemic Fungal Infections. September 5-7, Nijmejen, The Netherlands. Program and Abstract book, p53, Abstr.P5.

Stanley, R. J., McCaffrey, T. V., Weiland, L. H. (1988) Fungal mastoiditis in the immunocompromised host. Archives of Otolaryngology, Head and Neck Surgery 114(2): 198-199.

Strauss, M., Fine, E. (1991) Aspergillus otomastoiditis in acquired immunodeficiency syndrome. American Journal of Otolaryngology 12: 49-53.

Address for correspondence:

Mr P. D. Yates,

220 Belmont Road,

Bolton,

Lancashire BL1 7AZ. 